\title{
RECEPÇÃO, REPRISTINAÇÃO, DESCONSTITUCIONALIZAÇÃO E MUTAÇÃO CONSTITUCIONAL
}

\section{RECEPTION, REPRISTINATION, DECONSTITUTIONALIZATION ADN CONSTITUTIONAL CHANGE}

Reis Friede*

Resumo: o presente artigo discorre sobre o conceito e a classificação das normas constitucionais, analisando, ainda, os fenômenos da recepção, repristinação, desconstitucionalização e mutação constitucional. Para tal, utilizou-se primeiramente o método de pesquisa bibliográfica, com a finalidade de apresentar os conceitos basilares desse estudo. E, no tocante aos objetivos, seguiu-se a pesquisa descritiva, uma vez que o objetivo central é identificar os fatores que determinam ou influenciam para a ocorrência da geração dos fenômenos. Como resultado, o presente estudo visa contribuir com o entendimento e estruturação dos fenômenos de direito intertemporal no que se refere às normas constitucionais.

Palavras-chave: Norma Constitucional. Direito Intertemporal. Recepção. Repristinação. Mutação.

Abstract: This paper discusses the concept and classification of constitutional rules, analyzing the phenomena of reception, repristination, deconstitutionalization and constitutional change. For this, the bibliographic research method was first used, with the purpose of presenting the basic concepts of this study. And, regarding the objectives, the descriptive research followed, since the central objective is to identify the factors that determine or influence the occurrence of the generation of phenomena. As a result, the present study aims to contribute to understand and structure of intertemporal law phenomena with regard to constitutional norms.

Keywords: Constitutional rules. Intertemporal Law. Reception. Repristination. Constitutional Change.

\footnotetext{
* Desembargador Federal, Presidente do Tribunal Regional Federal da 2a Região (biênio 2019/21), Mestre e Doutor em Direito e Professor Adjunto da Universidade Federal do Estado do Rio de Janeiro (UNIRIO). Site: https://reisfriede.wordpress.com/. E-mail: reisfriede@hotmail.com.
} 


\section{INTRODUÇÃO}

No mundo ocidental, apesar de ter suas origens na antiguidade e Idade Média, o constitucionalismo surge com as Revoluções Liberais do Século XVIII, visando limitar o poder do Estado. A ideia era ter uma lei fundamental, à qual se submetesse também o governando, abandonando o poder absoluto e agindo nos termos de regras gerais que regulavam, principalmente, as formas e limites ao exercício do poder.

Considerando o foco liberal dessa mudança de paradigma, verifica-se que o objetivo era a liberdade individual para contratar e exercer o direito de propriedade.

Em um segundo momento, em meados do Século XIX e início do Século XX, após a Revolução Industrial e, marcadamente, após a Crise de 1929, um novo paradigma de Estado se revela, o Estado Social, ao qual se impunham obrigações de atuar na promoção das desigualdades materiais, reveladas principalmente na relação dono de capital x proletário.

Após a $2^{\mathrm{a}}$ Guerra Mundial, mesmo com direitos individuais e sociais garantidos nos textos constitucionais, esses são elevados a outro patamar, qual seja, o de fundamentar a existência do próprio Estado, que passa a existir em razão dos ditames da dignidade humana. Nesse contexto, a Constituição é ressignificada, ocupando o topo das ordens jurídicas internas, trazendo princípios e regras que deixam de ser apenas vetores de interpretação e integração do ordenamento e passam a ser normas coercitivas, superiores às demais e que irradiam para todos os ramos do Direito.

Em razão de tais fatores, o controle de constitucionalidade e a atuação do Poder Judiciário ou das Cortes Constitucionais também adquirem uma maior importância no cenário estatal, pois passam a controlar os atos dos demais poderes que contrariam o texto constitucional.

Desse modo, a jurisdição constitucional se tornou mais complexa, fazendo-se necessário compreender os institutos relacionados à interpretação, vigência, validade e eficácia das normas constitucionais. Neste estudo, analisaremos três teorias a eles associadas, a saber: a recepção, a repristinação e a desconstitucionalização. 


\section{CONTROLE DE CONSTITUCIONALIDADE}

Conforme elucida Ferrajoli, vivenciamos o paradigma do Estado Constitucional de Direito ou do constitucionalismo rígido, que se caracteriza pela "subordinação da própria lei, garantida por uma específica jurisdição de legitimidade, a uma lei superior: a constituição, hierarquicamente supraordenada à legislação ordinária." (FERRAJOLI, 2006, p. 424).

Assim explicita o mencionado autor:

[...] No Estado constitucional de Direito, as leis são submetidas não só a normas formais sobre produção, mas também a normas substanciais sobre 0 seu significado. De fato, não são admitidas normas legais, cujo significado esteja em contraste com normas constitucionais. A existência ou vigor das normas, que no paradigma paleojuspositivista tinham sido separadas da justiça, separam-se agora, também, da validade, tornando possível que uma norma formalmente validade e, portanto, vigente, seja substancialmente inválida quando o seu significado estiver em contraste com normas constitucionais substanciais, como, por exemplo, o princípio da igualdade ou os direitos fundamentais [...]. (FERRAJOLI, 2006, p. 425).

No Direito Brasileiro, isso se evidencia pela rigidez constitucional demonstrada pelo quórum elevado e mais dificultoso para se aprovar uma alteração no texto constitucional (emendas constitucionais) do que para aprovar uma lei ordinária. Além disso, há que se ressaltar a existência das cláusulas pétreas, que não podem ser modificadas nem mesmo por força de emenda constitucional, conforme previsão do art. 60 da Constituição Federal de 1988:

Art. 60. A Constituição poderá ser emendada mediante proposta:

I - de um terço, no mínimo, dos membros da Câmara dos Deputados ou do Senado Federal;

II - do Presidente da República;

III - de mais da metade das Assembléias Legislativas das unidades da Federação, manifestando-se, cada uma delas, pela maioria relativa de seus membros.

$\S 1^{\circ} \mathrm{A}$ Constituição não poderá ser emendada na vigência de intervenção federal, de estado de defesa ou de estado de sítio.

$\S 2^{\circ}$ A proposta será discutida e votada em cada Casa do Congresso Nacional, em dois turnos, considerando-se aprovada se obtiver, em ambos, três quintos dos votos dos respectivos membros.

$\S 30 \mathrm{~A}$ emenda à Constituição será promulgada pelas Mesas da Câmara dos Deputados e do Senado Federal, com o respectivo número de ordem.

§ $4^{\circ}$ Não será objeto de deliberação a proposta de emenda tendente a abolir:

I - a forma federativa de Estado;

II - o voto direto, secreto, universal e periódico; 


\title{
III - a separação dos Poderes; \\ IV - os direitos e garantias individuais. (BRASIL, 1988, não paginado, grifo nosso).
}

Decorre da supremacia da constituição e de sua rigidez que as normas inferiores devem estar de acordo com as constitucionais. A noção de inconstitucionalidade, então, se exprime pela não adequação de uma lei ou ato normativo ao texto constitucional, seja formalmente, quando não é seguido o processo legislativo constitucionalmente previsto para a criação de uma lei, ou materialmente, quando a própria substância do documento legal vai de encontro aos valores expressos pelas normas constitucionais.

Conforme orientações de Gilmar Mendes e Paulo Branco, o efeito da inconstitucionalidade é a nulidade ou anulabilidade da norma inconstitucional, que é retirada do mundo jurídico, assim que se dá a declaração da sua inconstitucionalidade:

\begin{abstract}
Dessarte, os conceitos de constitucionalidade e inconstitucionalidade não traduzem, tão somente, a ideia de conformidade ou inconformidade com a Constituição. Assim, tomando de empréstimo a expressão de Bittar, dir-se-á que constitucional será 0 ato que não incorrer em sanção, por ter sido criado por autoridade constitucionalmente competente e sob a forma que a Constituição prescreve para sua perfeita integração; inconstitucional será o ato que incorrer em sanção - de nulidade ou de anulabilidade - por desconformidade com o ordenamento constitucional. (MENDES; BRANCO, 2019, p. 1174).
\end{abstract}

Contudo, há que distinguir os casos em que a norma legal é posterior à Constituição, onde tipicamente tem-se a análise da constitucionalidade da norma, ou se é caso de uma contradição entre uma norma anterior à constituição vigente. Nesse caso, não se discute a constitucionalidade ou inconstitucionalidade da lei anterior, mas sim se a mesma foi recepcionada ou não pela nova ordem constitucional, ou seja, se foi revogada pela constituição.

Destaca-se que a não recepção apenas se dá por critérios materiais, de conteúdo, sendo mantidas no ordenamento jurídico normas anteriores que possuem formas revogadas pela nova constituição. No caso, as leis são recepcionadas em conformidade com o nova ordem constitucional, mudando o seu status no ordenamento. 
Dentre os institutos de direito intertemporal do Direito Constitucional, serão analisados o da recepção, repristinação, desconstitucionalização e mutação constitucional.

\section{RECEPÇÃO}

Nos termos do art. $2^{\circ}, \S 1^{\circ}$, da Lei de Introdução às Normas do Direito Brasileiro, Decreto-Lei no 4.657/42 (BRASIL, 1942), a lei nova (em seu sentido amplo) revoga a anterior quando expressamente o declare (revogação expressa), quando seja com ela incompatível ou quando regule inteiramente a matéria de que tratava a lei anterior (revogação tácita), o que pode ocorre total (ab-rogação) ou parcialmente (derrogação).

Nesse contexto, a questão central consiste em saber quando o advento de um novo Texto Constitucional acarreta a revogação de uma norma infraconstitucional anterior. Em resposta, cumpre ter em vista que a nova ordem constitucional inaugurada sempre recebe a normatividade infraconstitucional que lhe é perfeitamente compatível, ainda que tal acolhimento possa ocorrer a partir de uma nova "roupagem normativa", originando, pois, o fenômeno da recepção, segundo o qual a legislação infraconstitucional produzida antes da instalação de uma nova Constituição será considerada acolhida pelo novel Texto Magno, continuando, por princípio de economia e segurança legislativa, a viger no âmbito próprio de sua atuação ordinária.

\footnotetext{
Assim, com o propósito de evitar-se o infindável trabalho de reiniciar a construção do sistema de normas ordinárias, apercebeu-se que muito mais apropriado e coerente seria fazer com que as leis inferiores à Constituição pudessem ser aproveitadas quando compatíveis com as normas constitucionais, originando, desse modo, o fenômeno chamado de recepção constitucional.

Com isso, no Brasil, aplica-se o princípio da continuidade da Ordem Jurídica, que significa o aproveitamento dos atos legislativos anteriores quando compatíveis com a nova Constituição. (SILVA NETO, 2009, p. 145).
}

De qualquer modo, importante frisar que, excepcionalmente, a lei anterior poderá adquirir um novo "rótulo normativo" (dentro do espectro legislativo infraconstitucional), exatamente o que se sucedeu, por exemplo, com o Código Penal 
de 1940, editado sob a vigência da Carta de 1937, ocasião em que era perfeitamente possível tratar de matéria penal por meio de decreto-lei (Decreto-Lei no 2.848/40), o que não mais se admite na presente quadra, tendo em vista que, de acordo com o art. 22, inciso I, da Constituição de 1988, cabe ao Congresso Nacional legislador sobre Direito Penal. Com efeito, diante da incidência do fenômeno em epígrafe, é possível concluir que o Código Penal de 1940 restou recepcionado como lei ordinária pelo Texto Constitucional atual.

\section{REPRISTINAÇÃO}

Por outro lado, pode ocorrer que uma determinada lei ordinária $(\mathbf{X})$ tenha sido tacitamente revogada (vale dizer, não recepcionada) por uma Constituição posterior (Y), a qual, em um momento seguinte, deixa de vigorar ante o advento de uma nova Carta Fundamental (Z). Verifica-se, ademais, que a referida lei ordinária $(\mathbf{X})$, isto é, aquela que não havia sido recepcionada pela Constituição $(\mathbf{Y})$, revela-se, agora, perfeitamente compatível com a nova Lei Maior (Z), donde surge a seguinte dúvida: tal quadro permitiria a restauração da vigência da lei ordinária $(\mathbf{X})$ ?

Em resposta, cumpre registrar que, por questão de segurança jurídica, tal fenômeno, denominado de repristinação, somente é admitido, em nossa legislação, quando expressamente previsto e autorizado, conforme preconiza, inclusive, 0 art. $2^{\circ}$, parágrafo $3^{\circ}$, da Lei de Introdução às Normas do Direito Brasileiro (Decreto-Lei no 4.657/42), segundo o qual "salvo disposição em contrário, a lei revogada não se restaura por ter a lei revogadora perdido a vigência". Sem embargo desta possibilidade excepcional, e conforme bem adverte Silva Neto, não nos parece conveniente proceder à repristinação de lei já revogada, tendo em vista a possibilidade de se instaurar um quadro de insegurança jurídica.

No que concerne à repristinação, ou seja, a possibilidade de restauração da eficácia da norma revogada pela perda de vigência da norma revogadora, não nos parece que o mero advento de um novo texto constitucional tenha o condão de restaurar a eficácia de lei ordinária revogada pela Constituição anterior.

E por quê? Basicamente em virtude do fato de tal procedimento instilar grande insegurança nas relações jurídicas, cujos efeitos já se consolidaram, tornando, portanto, impróprio o retorno à situação antecedente. (SILVA NETO, 2009, p. 146). 
Destarte, no cenário hipotético examinado, a edição da Constituição (Z) por si só não restauraria, de modo automático, a vigência da lei ordinária (X).

\section{DESCONSTITUCIONALIZAÇÃO}

Por desconstitucionalização entende-se:

Fenômeno pelo qual as normas da Constituição anterior, desde que compatíveis com a nova ordem, permanecem em vigor, mas com o status de lei infraconstitucional. Ou seja, as normas da Constituição anterior são recepcionadas com o status de norma infraconstitucional pela nova ordem." (LENZA, 2012, p. 202-203).

Sem embargo de sua admissão por alguns autores nacionais e estrangeiros, fato é que tal fenômeno não tem se verificado no âmbito das Constituições Federais, não obstante ser possível sob o prisma teórico, desde que a nova Constituição expressamente autorize a manutenção, enquanto legislação infraconstitucional, de dispositivos integrantes da Carta anterior. Até mesmo porque, conforme cediço, "o Poder Constituinte Originário é ilimitado e autônomo, podendo tudo, inclusive prever o aludido fenômeno, mas desde que o faça, como visto, de maneira inequívoca e expressa" (LENZA, 2012, p. 203).

A ordem constitucional nova, por ser tal, é incompatível com a ordem constitucional antiga. Aquela revoga esta.

Entretanto, não há necessidade de nova produção legislativa infraconstitucional.

A Constituição nova recebe a ordem normativa que surgiu sob o império de Constituições anteriores se com ela forem compatíveis.

É o fenômeno da recepção que se destina a dar continuidade às relações sociais sem necessidade de nova, custosa, difícil e quase impossível manifestação legislativa ordinária.

Ressalte-se, porém, que a nova ordem constitucional recepciona os instrumentos normativos anteriores dando-lhes novo fundamento de validade e, muitas vezes, nova roupagem.

Explica-se: com o advento de nova Constituição, a ordem normativa anterior, comum, perde seu antigo fundamento de validade para, em face da recepção, ganhar novo suporte. Da mesma forma, aquela legislação, ao ser recebida, ganha a natureza que a Constituição nova atribui a atos regentes de certas matérias. Assim, leis anteriores tidas por ordinárias podem passar a complementares, decretos-leis podem passar a ter a natureza de leis ordinárias.

Se isto ocorre com a legislação imediatamente anterior, pergunta-se: A Constituição nova recebe, também, a legislação nascida sob o império de Constituições revogadas pela que a antecedeu e que, em face desta, 
perderam sua eficácia? A nova Constituição restaura, automaticamente, a legislação aludida? A resposta é negativa.

A legislação infraconstitucional que perdeu sua eficácia diante de um texto constitucional não se restaura pelo surgimento de nova Constituição.

Essa restauração de eficácia é categorizável como repristinação, inadmitida em nome do princípio da segurança e da estabilidade das relações sociais. 0 permanente fluxo e refluxo de legislação geraria dificuldades insuperáveis ao aplicador da lei, circunstância não desejada pelo Constituinte.

Uma hipótese de repristinação, entretanto, é possível, lembra CELSO BASTOS: a de sua previsão expressa.

Outra preocupação é a que se refere à possibilidade de recepção, pela nova ordem constitucional, como leis ordinárias, de disposições da Constituição anterior. É a chamada teoria da desconstitucionalização.

No particular, ficamos com CELSO BASTOS, para quem a tese da desconstitucionalização não é de ser aceita, em nosso entender, uma vez que as antigas leis constitucionais não encontram explicação para serem rebaixadas à categoria de leis ordinárias sem disposições nesse sentido na nova Constituição. (TEMER, 1989, p. 39-40).

\section{MUTAÇÃO CONSTITUCIONAL}

Cabe analisar, em particular, a questão inerente à interpretação judicial como mecanismo para promover a chamada mutação constitucional, fenômeno que Bulos descreve como sendo:

O processo informal de mudanças da Constituição, por meio do qual são atribuídos novos sentidos, conteúdos até então não ressaltados à letra da lex legum, quer através da interpretação, em suas diversas modalidades e métodos, quer por intermédio da construção (construction), bem como dos usos e costumes constitucionais. (BULOS, 1997, p. 54).

A origem da figura jurídica em tela, segundo leciona Kublisckas (2009, p. 70) teria surgido pela lavra de PAUL LABAND (Die Wandlungen der deutschen Reichsverfassung, de 1895), particularmente ao estabelecer a distinção entre reforma constitucional (Verfassungänderung) e mutação constitucional (Verfassungswandlung). Concordando com a mesma origem histórica, assevera o Ministro EROS GRAU:

Impõe-se neste ponto, parenteticamente, brevíssima digressão a propósito da mutação constitucional, fenômeno discernido por LABAND, mas do qual terá sido GEORG JELLINEK o primeiro a tratar no plano teórico. A nova doutrina do direito político, recusando explicações ancoradas em perspectiva formalista, caracteriza-a, qual anota HSÜ DAU-LIN, como desvalorização e corrosão das normas jurídicas constitucionais por ela afetadas. A mutação constitucional decorre de uma incongruência existente entre as normas 
constitucionais e a realidade constitucional, entre a Constituição formal e a Constituição material. (BRASIL, 2014, p. 73).

Ainda sob uma perspectiva histórica, recorda Botelho:

Buscando fundamentação no princípio do stare decisis e na história constitucional norte-americana, a Suprema Corte considerou que a superação de precedentes é apropriada quando ocorrem mudanças nas circunstâncias fáticas ou na compreensão desses fatos, lançando dúvidas sobre verdades atemporais, paradigmas ou princípios supostamente neutros, que não mais são capazes de solucionar questões constitucionais. (BOTELHO, 2011, p. 19).

Segundo o Ministro Eros Grau (Reclamação no 4.335/AC), a mutação constitucional consiste em se promover uma transformação no sentido do enunciado da Constituição, sem que se empreenda, para tanto, qualquer alteração na redação do próprio texto, vale dizer, na sua dimensão constitucional textual.

Quando ela se dá, o intérprete extrai do texto norma diversa daquelas que nele se encontravam originariamente involucradas, em estado de potência. Há, então, mais do que interpretação, esta concebida como processo que opera a transformação de texto em norma. Na mutação constitucional caminhamos não de um texto a uma norma, porém de um texto a outro texto, que substitui o primeiro.

Daí que a mutação constitucional não se dá simplesmente pelo fato de um intérprete extrair de um mesmo texto norma diversa da produzida por outro intérprete. Isso se verifica diuturnamente, a cada instante, em razão de ser, a interpretação, uma prudência. Na mutação constitucional há mais. Nela não apenas a norma é outra, mas o próprio enunciado normativo é alterado. (BRASIL, 2014, p. 72).

Em uma nítida referência ao fenômeno em epígrafe, cumpre registrar que o Ministro Celso de Mello (BRASIL, 2009), quando do julgamento, em 23.09.2008, do Habeas Corpus no 91.361/SP, destacou a relevância da "interpretação judicial como instrumento juridicamente idôneo de mudança informal da Constituição", bem como:

A legitimidade da adequação, mediante interpretação do Poder Judiciário, da própria Constituição da República, se e quando imperioso compatibilizá-la, mediante exegese atualizadora, com as novas exigências, necessidades e transformações resultantes dos processos sociais, econômicos e políticos que caracterizam, em seus múltiplos e complexos aspectos, a sociedade contemporânea. (BRASIL, 2009, p. 2).

Em outra ocasião, Celso de Mello, também atento às mudanças sociais que demandam uma nova leitura do Texto Magno, aptas a ensejar o fenômeno em comento, explica que "o exercício da jurisdição constitucional, que tem por objetivo 
preservar a supremacia da Constituição, põe em evidência a dimensão essencialmente política em que se projeta a atividade institucional do Supremo Tribunal Federal, pois, no processo de indagação constitucional, assenta-se a magna prerrogativa de decidir, em última análise, sobre a própria substância do poder", concluindo, então, que "no poder de interpretar a Lei Fundamental reside a prerrogativa extraordinária de (re)formulá-la, eis que a interpretação judicial acha-se compreendida entre os processos informais de mutação constitucional, a significar, portanto, que 'a Constituição está em elaboração permanente nos Tribunais incumbidos de aplicá-la'. Por conseguinte, conclui o Ministro que

A interpretação constitucional derivada das decisões proferidas pelo Supremo Tribunal Federal assume papel de fundamental importância na organização institucional do Estado brasileiro, a justificar o reconhecimento de que o modelo político-jurídico vigente em nosso País conferiu, à Suprema Corte, a singular prerrogativa de dispor do monopólio da última palavra em tema de exegese das normas inscritas no texto da Lei Fundamental. (BRASIL, 2008).

Em outro julgado em que se debateu sobre o mesmo tema, anotou o Ministro Luiz Fux que:

O hodierno marco teórico dos diálogos constitucionais repudia a adoção de concepções juriscêntricas no campo da hermenêutica constitucional, na medida em que preconiza, descritiva e normativamente, a inexistência de instituição detentora do monopólio do sentido e do alcance das disposições magnas, além de atrair a gramática constitucional para outros fóruns de discussão, que não as Cortes. (BRASIL, 2015, p. 2).

Assim, segundo o Ministro Fux,

O princípio fundamental da separação de poderes, enquanto cânone constitucional interpretativo, reclama a pluralização dos intérpretes da Constituição, mediante a atuação coordenada entre os poderes estatais Legislativo, Executivo e Judiciário - e os diversos segmentos da sociedade civil organizada, em um processo contínuo, ininterrupto e republicano, em que cada um destes players contribua, com suas capacidades específicas, no embate dialógico, no afã de avançar os rumos da empreitada constitucional e no aperfeiçoamento das instituições democráticas, sem se arvorarem como intérpretes únicos e exclusivos da Carta da República. (BRASIL, 2015, p. 2-3).

Com efeito, para Luiz Fux:

O desenho institucional erigido pelo constituinte de 1988, mercê de outorgar à Suprema Corte a tarefa da guarda precípua da Lei Fundamental, não erigiu um sistema de supremacia judicial em sentido material (ou definitiva), de maneira que seus pronunciamentos judiciais devem ser compreendidos 
como última palavra provisória, vinculando formalmente as partes do processo e finalizando uma rodada deliberativa acerca da temática, sem, em consequência, fossilizar o conteúdo constitucional. (BRASIL, 2015, p. 3).

Na mesma linha de pensamento, o Ministro GILMAR MENDES registrou que, "com base na alegação de afronta a determinada decisão do STF, o Tribunal poderá reapreciar e redefinir o conteúdo e o alcance de sua própria decisão", podendo, inclusive superar (total ou parcialmente) "a decisão-parâmetro da reclamação, se entender que, em virtude de evolução hermenêutica, tal decisão não se coaduna mais com a interpretação atual da Constituição." (BRASIL, 2013, p. 2).

Não obstante, quando do julgamento da Reclamação no 4.335/AC, o Ministro Ricardo Lewandowski, ao proferir o seu voto, advertiu que "os próprios teóricos da mutação constitucional reconhecem que esse fenômeno possui limites", sob pena de redundar em "mutações inconstitucionais." (BRASIL, 2014, p. 10).

Da dicção levada a efeito pelos referidos Ministros extrai-se uma afirmação comum: a possibilidade de a Suprema Corte, motivada pelas atuais demandas da sociedade, proceder a uma nova exegese do Texto Constitucional, ainda que a redação do dispositivo sobre o qual recai a tarefa interpretativa permaneça o mesmo, proceder que, no entanto, encontra limites, conforme registrado pelo Ministro RICARDO LEWANDOWSKI.

\section{CONSIDERAÇÕES FINAIS}

Diante do exposto, é possível aferir que a complexidade na aplicação das normas constitucionais, principalmente quando se trata do surgimento de uma nova Constituição (regras de direito intertemporal), acompanhou o próprio crescimento na importância e abrangência do Direito Constitucional.

No Brasil, em razão de termos uma constituição prolixa, que cuida de inúmeros assuntos, sejam eles materialmente constitucionais ou não, e também em virtude da irradiação das normas constitucionais sobre as demais normas do Direito, o papel da interpretação constitucional se torna cada vez mais relevante.

Deste modo, cabe à doutrina e jurisprudência o desenvolvimento de tais institutos e a delimitação dos respectivos conceitos e fenômenos, a fim de propiciar o 
melhor entendimento da interpretação e aplicação das normas constitucionais no país. Nesse sentido, o presente estudo objetiva contribuir com a estruturação dos fenômenos de direito intertemporal, aplicáveis às normas constitucionais, quais sejam: recepção, repristinação, desconstitucionalização e mutação constitucional.

\section{REFERÊNCIAS}

BOTELHO, Nadja Machado. Mutação Constitucional: a Constituição Viva de 1988. Rio de Janeiro: Lumen Juris, 2011.

BULOS, Uadi Lammêgo. Mutação Constitucional. São Paulo: Saraiva, 1997.

BRASIL. [Constituição (1988)]. Constituição da República Federativa do Brasil de 1988. Brasília, DF: Presidência da República, [2016]. Disponível em: http://www.planalto.gov.br/ccivil_03/Constituicao/ Constituiçao.htm. Acesso em: 20 ago. 2019.

Decreto-lei no 4.657, de 4 de setembro de 1942. Lei de Introdução às normas do Direito Brasileiro. Rio de Janeiro: Presidência da República, 1942. Disponível em: http://www.planalto.gov.br/ccivil_03/decretolei/del4657compilado.htm. Acesso em: 20 ago. 2019.

\section{. Supremo Tribunal Federal. Ação Direta de Inconstitucionalidade}

no 5.105 Distrito Federal. Tribunal Pleno. Relator: Min. Luiz Fux, 01 de outubro de 2015. [Brasília], 1 out. 2015. Inteiro Teor do Acórdão. Disponível em:

http://redir.stf.jus.br/paginadorpub/paginador.jsp?docTP=TP\&docID=10499116. Acesso em: 20 ago. 2019.

. Supremo Tribunal Federal (2. Turma). Habeas Corpus no 91.361-0

São Paulo. Coordenadoria de Análise de Jurisprudência. Relator: Min. Celso de Mello, 23 de setembro de 2008. Diário da Justiça Eletrônico: [Brasília], n. 25, 06 fev. 2009. Disponível em:

http://redir.stf.jus.br/paginadorpub/paginador.jsp?docTP=AC\&docID=573717. Acesso em: 20 ago. 2019.

. Supremo Tribunal Federal. Mandado de Segurança no 26.603/DF, Tribunal Pleno. Relator: Min. Eros Grau, 4 de outubro 2007. Diário da Justiça Eletrônico: [Brasília], n. 197, 17 out. 2008. Disponível em:

https://stf.jusbrasil.com.br/jurisprudencia/2928434/mandado-de-seguranca-ms26602-df?ref=feed. Acesso em: 20 ago. 2019.

. Supremo Tribunal Federal. Reclamação no 4.335 Acre. Coordenadoria de Análise de Jurisprudência. Relator: Min. Gilmar Mendes, 20 de março de 2014. Diário da Justiça Eletrônico: [Brasília], n. 208, 22 out. 2014. Disponível em: 
http://redir.stf.jus.br/paginadorpub/paginador.jsp?docTP=AC\&docID=630101. Acesso em: 20 ago. 2019. . Supremo Tribunal Federal. Reclamação 4.374 Pernambuco.

Tribunal Pleno. Relator: Min. Gilmar Mendes, 18 de abril de 2013. [Brasília], 18 abr. 2013. Inteiro Teor do Acórdão. Disponível em: http://redir.stf.jus.br/paginadorpub/paginador.jsp?docTP=TP\&docID $=4439489$. Acesso em: 20 ago. 2019.

FERRAJOLI, Luigi. O Estado de Direito entre o passado e o futuro. In: COSTA, Pietro; ZOLO, Danilo (org.). O Estado de Direito: história, teoria, crítica. Tradução: Cario Alberto Dastoli. São Paulo: Martins Fontes, 2006.

MENDES, Gilmar Ferreira; BRANCO, Paulo Gustavo Gonet. Curso de Direito Constitucional. 14. ed. rev. e atual. São Paulo: Saraiva Educação, 2019.

KUBLISCKAS, Wellington. Emendas e Mutações Constitucionais: Análise dos Mecanismos de Alteração Formal e Informal da Constituição Federal de 1988. São Paulo, Atlas, 2009.

LENZA, Pedro. Direito Constitucional Esquematizado, 16. ed. São Paulo: Saraiva, 2012.

SILVA NETO, Manoel Jorge e. Curso de Direito Constitucional. 4. ed. Rio de Janeiro: Lumen Juris, 2009.

TEMER, Michel. Elementos de Direito Constitucional, 5. ed. São Paulo: Revista dos Tribunais, 1989. 